Philippe Grönquist*, Thomas Schnider, Andreas Thoma, Fabio Gramazio, Matthias Kohler, Ingo Burgert and Markus Rüggeberg

\title{
Investigations on densified beech wood for application as a swelling dowel in timber joints
}

https://doi.org/10.1515/hf-2018-0106

Received May 4, 2018; accepted November 29, 2018; previously published online January 11, 2019

Abstract: For robotic fabrication of wooden structures, the simple, quick and tight joining of elements can be solved using swelling hardwood dowels. This topic has been the focus of the present study, and the set-recovery capacity of densified wood (dW) as dowel material was investigated. European beech was compressed in the radial direction at $103^{\circ} \mathrm{C}$ and $10 \%$ moisture content (MC) to a compression ratio of $40 \%$. Multiple swelling and shrinkage cycles were applied to measure swelling behavior, swelling pressure development and combined swelling and creep under compressive loading. It has been demonstrated that dW shows increased swelling and more persisting swelling pressures than native wood (nW). The set-recovery prevents significant contact-stress relaxation over multiple cycles of MC change. Application as a structural joining element for robotic fabrication was studied by shear lap joint tests on round double-dovetail swelling dowels.

Keywords: creep, densified wood, dovetail swelling dowel, European beech, robotic fabrication, set-recovery, swelling coefficient, swelling pressure

\footnotetext{
*Corresponding author: Philippe Grönquist, Empa, Laboratory for Applied Wood Materials, Überlandstrasse 129, 8600 Dübendorf, Switzerland; and Institute for Building Materials, ETH Zurich, Stefano-Franscini-Platz 3, 8093 Zurich, Switzerland, e-mail: philippe.groenquist@empa.ch. https://orcid.org/00000001-8432-1706

Thomas Schnider: Institute for Building Materials, ETH Zurich, Stefano-Franscini-Platz 3, 8093 Zurich, Switzerland

Andreas Thoma, Fabio Gramazio and Matthias Kohler: Institute of Technology in Architecture, ETH Zurich, Stefano-Franscini-Platz 1, 8093 Zurich, Switzerland

Ingo Burgert and Markus Rüggeberg: Empa, Laboratory for Applied Wood Materials, Überlandstrasse 129, 8600 Dübendorf, Switzerland; and Institute for Building Materials, ETH Zurich, Stefano-Franscini-Platz 3, 8093 Zurich, Switzerland
}

Introduction

Wood and wood-based products are well-suited materials in the emerging field of digital fabrication of engineering structures (Gramazio and Kohler 2014; Adriaenssens et al. 2016; Menges et al. 2017a,b), which are assembled by robotic fabrication. Optimization of such processes strongly depends on the connection of pre-fabricated wood elements composing a structure. Standard joining methods such as adhesive, nail, bolt and screw joints are based on a form-and-friction locking effect leading to a high rigidity of the assembled joint. Such joints require application of mechanical pressure to insert steel fasteners, or precise application of adhesives that imply significant impact on fabrication because of working and curing times of the adhesives. Simpler joining techniques would favor faster robotic fabrication routines.

Examples for joining of wood without adhesives or steel fasteners are hardwood pegs in historical timber constructions (Sandberg et al. 2000). The joining of elements with a certain degree of freedom for an initial movement, which is the case when swelling dowels or pegs are applied, is a tailored advantage for robotic fabrication. The concept allows for spatially arranging single parts after joining and for compensating tolerances in frame or truss structures during assembly. The hygroscopic behavior of wood resulting in swelling and shrinkage in response to changes in moisture content (MC) below the fiber saturation point (FSP) facilitates form-and-friction locking of dowels or pegs. Therefore, such a joint geometry can be designed in a predictive manner as a function of MC change and time.

Mechanically loaded wood, however, shows a rheological behavior because of the presence of amorphous polymers in the wood cell wall (Holzer et al. 1989). This can result in creep or relaxation via diminishing of internal stresses over time. Relaxation is highly affected by MC variations (Hering 2011; Ożyhar 2013). The contact pressure between connectors based on friction locking can, thus, decrease down to zero in the course of time as a function of relative humidity $(\mathrm{RH})$ decrement.

Compressed wood (densified wood, dW) as a connector can be a remedy because sufficient swelling pressure for 
friction-locked joints may be maintained because of the set-recovery effect (Navi and Heger 2005; Blomberg et al. 2006). dW was already developed and applied over a century ago (Blomberg 2006; Sandberg et al. 2013), while the wood is compressed at temperatures above the glass transition temperature $\left(T_{g}\right)$ of lignin. In this state, compression stiffness perpendicular to the fiber direction is drastically reduced allowing for a significant densification. However, the initially stable compressed state below $T_{g}$ becomes unstable upon contact with moisture or heat. The extent of shape recovery (set recovery) is dependent on the parameters of densification such as MC, heat and applied stress. In fact, wood is a composite polymer with shapememory effects (Ugolev 2014), which limits the industrial application of dW. Research on dW often focuses on permanent fixation of the densified state based on methods of chemical or thermal treatment before, during or after densification (Morsing and Hoffmeyer 1998; Navi and Girardet 2000; Wolcott and Shutler 2003; Blomberg 2006; Kutnar et al. 2008; Skyba 2008; Laine 2014; Palma et al. 2016). In contrast, shape recovery is beneficial in the case of dW as a structural swelling component (Jung et al. 2008; Guan et al. 2010). However, the mechanical behavior of $d W$ as a swelling dowel has not yet been studied.

The intention of the present study was to fill this gap focusing on the quantitative swelling behavior of beech $\mathrm{dW}$ as a function of MC variation over multiple cycles of moistening and drying. In this context, the swelling pressure (Blomberg and Persson 2007; Ispas 2013), the time-dependent mechanical response and swelling capacity of beech dW under load were addressed by measurements under RH change. Finally, cylindrical double-dovetail-shaped beech $\mathrm{dW}$ dowels were tested in comparison with native beech dowels in form-andfriction locking joints. Hereby, the joint geometry was designed based on the results of the previous characterization experiments.

\section{Materials and methods}

Wood densification: The samples were taken from two boards of European beech (Fagus sylvatica L.) $\left[650 \times 250 \times 60 \mathrm{~mm}^{3}(\mathrm{~L} \times \mathrm{T} \times \mathrm{R})\right]$ taken from the same stem originating from the region of Zurich, Switzerland. The boards were conditioned at $20^{\circ} \mathrm{C} / 65 \% \mathrm{RH}$ to a mean equilibrium MC (EMC) of $10 \%$ in adsorption. One board was compressed in the R-direction as illustrated in Figure 1 at $103^{\circ} \mathrm{C}$, which is above the lignin $T_{g}$, and which does not change the original structural integrity and permits to keep the maximum shape recovery. The pressure was then increased to $5 \mathrm{MPa}$ and further increased at $1 \mathrm{MPa}$ per $10 \mathrm{~min}$ steps to a final pressure of $\approx 8 \mathrm{MPa}$, which was kept for $30 \mathrm{~min}$. After $120 \mathrm{~min}$ cooling time, $70^{\circ} \mathrm{C}$ was

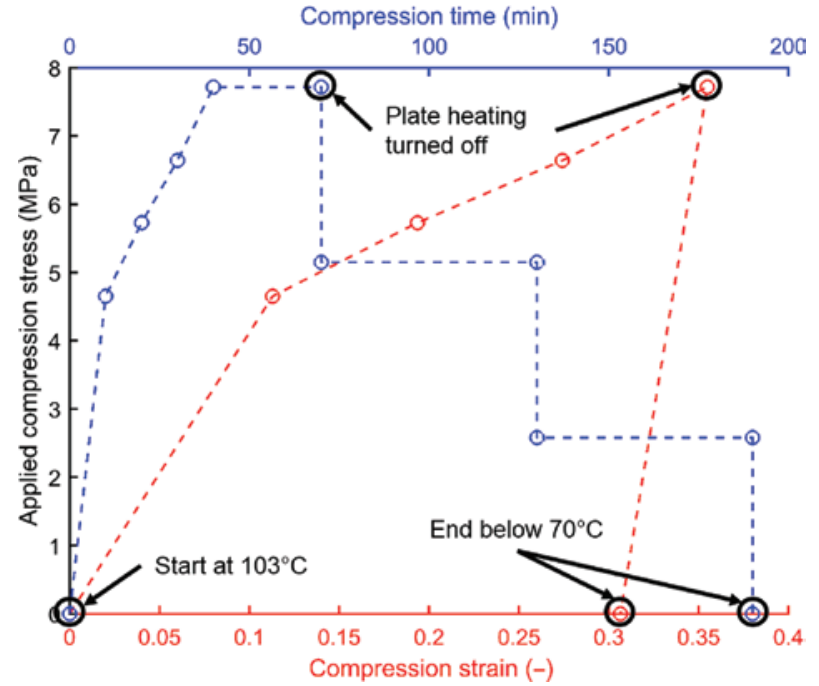

Figure 1: Densification procedure.

Applied pressure in the R-direction on board over time (blue, upper abscissa) and resulting compression strain (red, lower abscissa).

reached. The other board was left in the native state for reference specimens.

Free swelling behavior of beech $\mathrm{dW}$ : Samples with dimensions $20 \times 20 \times 10 \mathrm{~mm}^{3}(\mathrm{R} \times \mathrm{T} \times \mathrm{L})$ were produced from beech $\mathrm{dW}$ [mean value $\bar{x}_{\rho}=941 \mathrm{~kg} \mathrm{~m}^{-3}$, standard deviation (StD) $s_{\rho}=14 \mathrm{~kg} \mathrm{~m}^{-3}$ at $0 \% \mathrm{MC}$, $n=8]$ and from beech native wood (nW) $\left(\bar{x}_{\rho}=703 \mathrm{~kg} \mathrm{~m}^{-3}, s_{\rho}=7 \mathrm{~kg} \mathrm{~m}^{-3}\right.$ at $0 \% \mathrm{MC}, n=8$ ) as reference. The dimensions are according to DIN 52184:1979-05. The samples were oven-dried (o.d.) at $103^{\circ} \mathrm{C}$ until reaching mass constancy (less than $0.1 \%$ weight gain/loss over $24 \mathrm{~h}$ ), and then weight and dimensions were measured. Afterward, the samples were equilibrated at $85 \%$ RH. Weight and dimensions were recorded until mass constancy was reached. The samples were then again dried and this cycle was repeated 8 times. Differential swelling and shrinkage coefficients $(\alpha)$ were calculated in the R- and T-directions for all cycles by assuming a linear relation between swelling strain $\left(\varepsilon^{s w}=\Delta l \cdot l^{-1}\right)$ and MC change $(\Delta \omega)$, i.e. $\alpha=\varepsilon^{s w} \Delta \omega^{-1}$. MC $(\omega)$ was determined by the gravimetric method as $\omega=\left(m_{\omega}-m_{0}\right) m_{0}^{-1}$, where $m_{\omega}$ is the sample mass at an EMC of $\omega$ and $m_{0}$ is the o.d. sample mass.

Swelling pressure: One $\mathrm{nW}$ and one $\mathrm{dW}$ sample $\left(\rho=696 \mathrm{~kg} \mathrm{~m}^{-3}\right.$ and $986 \mathrm{~kg} \mathrm{~m}^{-3}$ at $\left.0 \% \mathrm{MC}\right)\left[30 \times 30 \times 10 \mathrm{~mm}^{3}(\mathrm{R} \times \mathrm{T} \times \mathrm{L})\right]$ were separately placed inside a bulk steel frame and restrained in the R- and T-directions by plates connected to load recording cells via screw threads. The positive-locking screw threads combined with double-nut systems and counterclockwise-drilled internal threads at the restraining plates allowed for a controlled application of initial pressure on the samples in both anatomical directions. The o.d. samples were placed inside the restraint. An initial pressure of $0.15 \mathrm{kN}$ was applied in the $\mathrm{R}$ - and T-directions, whereas the L-direction remained unrestrained. The samples were then conditioned at 70\% and 35\% RH for $168 \mathrm{~h}$, respectively, in an alternating manner for three moistening cycles (ending up at 70\% RH). Forces were recorded every 2 min.

Swelling under load: Swelling and simultaneous creep were analyzed under applied compressive load in the R-direction. Samples of 
$\mathrm{dW}\left(\bar{x}_{\rho}=891 \mathrm{~kg} \mathrm{~m}^{-3}, s_{\rho}=13 \mathrm{~kg} \mathrm{~m}^{-3}\right.$ at $\left.0 \% \mathrm{MC}\right)$ and $\mathrm{nW}\left(\bar{x}_{\rho}=695 \mathrm{~kg} \mathrm{~m}^{-3}\right.$, $s_{\rho}=3 \mathrm{~kg} \mathrm{~m}^{-3}$ at $\left.0 \% \mathrm{MC}\right),\left[30 \times 30 \times 10 \mathrm{~mm}^{3}(\mathrm{R} \times \mathrm{T} \times \mathrm{L})\right]$ were initially o.d. and then placed inside a lever system loading device equipped with displacement recorders on the samples in the direction of the applied loads (Bachtiar 2017). The upper limit of the uniaxial compression strength of the sample in the R-direction was taken from the maximum swelling pressure in the R-direction under biaxial constraints. Different loads were applied in the R-direction corresponding to 20 , 40,60 and $80 \%$ of the maximum swelling pressure. The samples were let to swell at $65 \% \mathrm{RH}$ for $168 \mathrm{~h}$ and were then relocated to $85 \%$ $\mathrm{RH}$ conditions during $168 \mathrm{~h}$. Then, the loading was removed and the samples were relaxed at $85 \% \mathrm{RH}$ for $48 \mathrm{~h}$. For both, dW and nW, one sample was let to freely swell.

Double shear lap joint tests with cylindrical dovetailed dowels: Five timber shear lap joints were manufactured from spruce (Picea abies) wood and beech dW dowels $\left(\bar{x}_{\rho}=1016 \mathrm{~kg} \mathrm{~m}^{-3}, s_{\rho}=10 \mathrm{~kg} \mathrm{~m}^{-3}\right.$ in $65 \%$ $\mathrm{RH})$ and five joints with nW dowels $\left(\bar{x}_{\rho}=720 \mathrm{~kg} \mathrm{~m}^{-3}, s_{\rho}=7 \mathrm{~kg} \mathrm{~m}^{-3}\right.$ in $65 \% \mathrm{RH})$. The connecting boards were manufactured with spruce wood $\left(\bar{x}_{\rho}=365 \mathrm{~kg} \mathrm{~m}^{-3}, s_{\rho}=11 \mathrm{~kg} \mathrm{~m}^{-3}\right.$ in $\left.65 \% \mathrm{RH}\right)$. The dowels and the holes in the spruce boards were milled by means of computer numerical controlled (CNC) router milling $( \pm 0.025 \mathrm{~mm}$ nominal precision). The geometry of the dowels and of the connecting boards is presented in Figure 2. The inclination angle of the rotational symmetric double-dovetail dowels was $2^{\circ}$. The narrower diameter of the holes in the spruce boards was $30 \mathrm{~mm}$ and the inclination angle was again $2^{\circ}$. This allowed the initial insertion of o.d. dowels (outer diameter of $29.5 \mathrm{~mm}$ ) with a tolerance of $0.5 \mathrm{~mm}$. Then, a swelling of around $2 \mathrm{~mm}$ was needed for a stable friction locking. Before swelling, out-of-plane movements (separation of dowel and board) were impeded, while the rotational degree of freedom of the joint was kept until the dowel had been fully swollen. The assembled joint was then equilibrated at $85 \% \mathrm{RH}$ and afterward mechanically tested using a displacement controlled universal testing machine. A load was applied on top of the middle spruce board on the joint (in the L-direction of spruce) so that the dowel-shearing occurred inside the symmetrically designed joint. The dowels were oriented in a way that the densified R-direction was aligned with the loading direction (annual rings perpendicular to the loading direction). For a better comparability, the loading was applied following the testing procedure according to DIN EN 26891:1991-07. The joint stiffness modulus $K_{\mathrm{s}}$, required for dimensioning a wood structure in terms of serviceability, was calculated for the obtained force-displacement $(F, v)$ curves. The mean value $\bar{x}_{K_{s}}$ over a configuration of $n$ samples is: $\bar{x}_{K_{s}}=0.75 n^{-1} \sum_{i}^{n}\left[0.4 F_{\text {max }, e s t, i}\left(v_{40 \%, i}-v_{10 \%, i}\right)^{-1}\right]$ with a reduction factor of 0.75 .

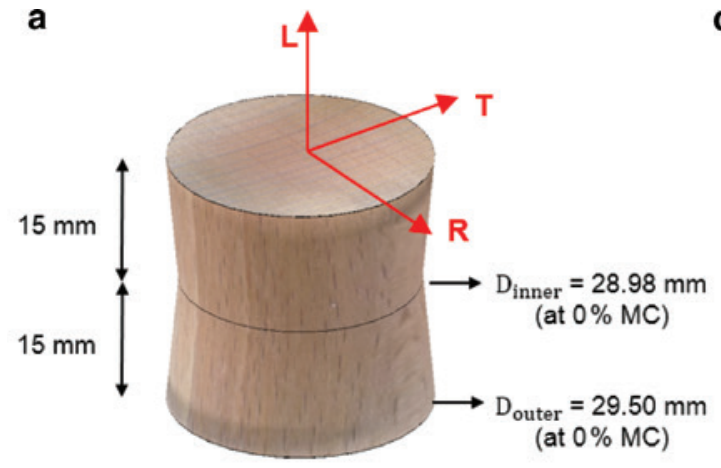

c
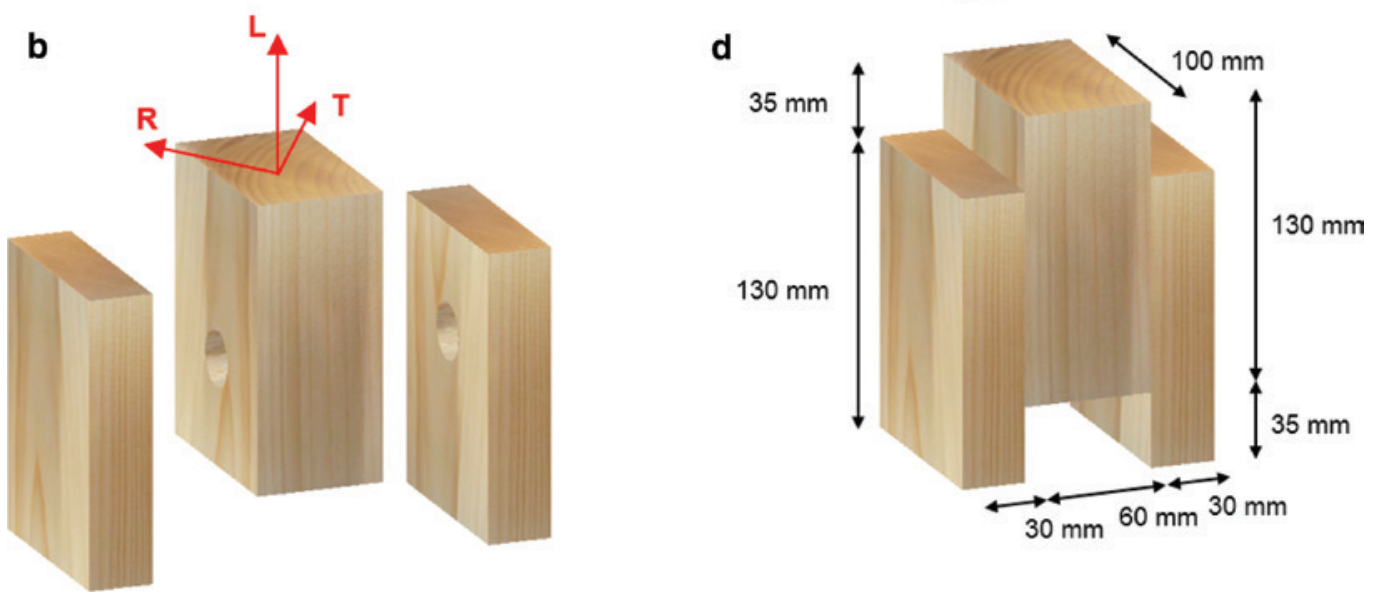

Figure 2: Geometrical setup for double lap shear joint tests.

(a) Geometry of rotational-symmetric double-dovetail swelling dowels, CNC milled, with an inclination angle of $2^{\circ}$ (D: diameter).

(b) Connecting spruce boards with two sideboards and a middle board, CNC milled negative dovetail forms with an insertion diameter of $30 \mathrm{~mm}$. (c) Dowel insertion. (d) Assembled joint with geometry. 


\section{Results and discussion}

\section{Wood density after densification}

A density of $1000 \mathrm{~kg} \mathrm{~m}^{-3}$ for beech wood at $10 \%$ MC was targeted by the applied compression routine. On an average, a compression ratio (CR, ratio of densities) of $40 \%$ was reached, although different regions in the board may have significantly different densities, for example, near the edges $\left(980 \mathrm{~kg} \mathrm{~m}^{-3}, \mathrm{CR}=36 \%\right)$ and in the middle (1084 $\left.\mathrm{kg} \mathrm{m}^{-3}, \mathrm{CR}=50 \%\right)$. Bulging of the edges was observed as a result of the uniaxial compression. Samples, thus, needed to be cut sequentially along the L-direction for comparability. A variability over thickness can also be expected because of the transversal densification (Kutnar et al. 2009). Figure 3 shows sample images before and after densification. Growth rings remained parallel, whereas the rays were diagonally shifted. In earlywood (EW) zones, this shift appears to be larger than in latewood (LW) zones as the rays completely buckle in EW. Accordingly, there is a pronounced heterogeneous morphology of densification.

\section{Free swelling behavior}

The $\mathrm{dW}$ shows a pronounced shape recovery and swelled about $30 \%$ in the R-direction $\left(\varepsilon_{R}\right)$ during eight cycles of o.d. and re-moistening at $85 \% \mathrm{RH}$ (Figure 4). The o.d. state dimensions at $\mathrm{t}=0$ served as reference lengths for strain calculation. About $50 \%$ of the entire swelling strain was already attained after the swelling step of the first cycle. The relative shape recovery decreased over further

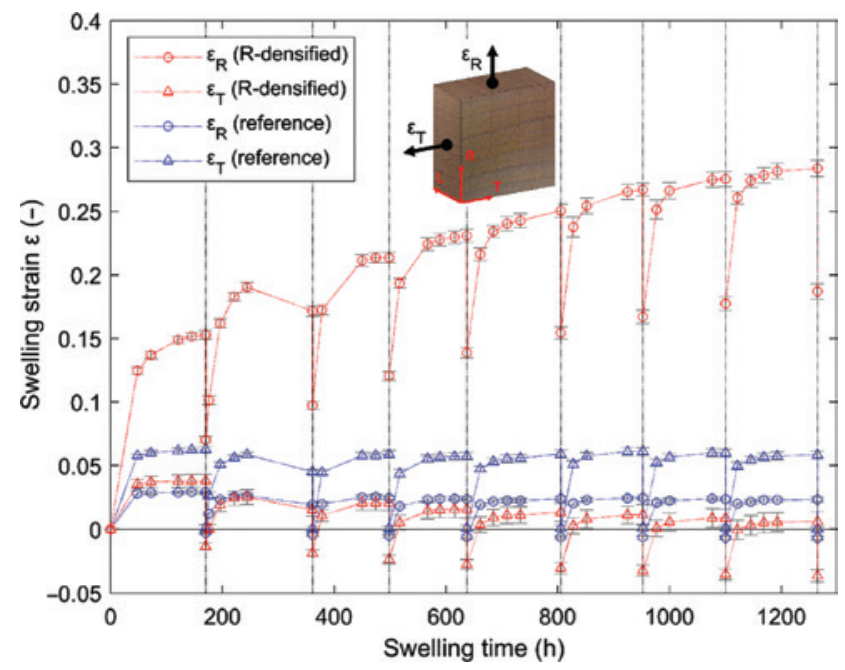

Figure 4: Recorded swelling strains of R-densified and of native beech samples over eight swelling and eight shrinkage cycles. Oven-dry dimensions at $\mathrm{t}=0$ represent reference lengths for strain calculation. Dotted lines represent linear interpolation between measured points. Vertical black dotted lines represent the end of swelling cycle, oven-drying (for $48 \mathrm{~h}$, not considered on the time axis) and the start of new swelling cycle. Markers represent mean values and gray error-bars represent positive and negative standard deviations.

swelling-shrinkage cycles, while the total shape recovery increased and showed an asymptotic behavior in accordance with the literature (Heger et al. 2004; Anshari et al. 2011; Laine et al. 2013; Buchelt et al. 2014). In contrast to the R-expansion, i.e. in the densification direction, a retraction was observed in the T-direction, which is visible as negative strain in the $\mathrm{o}$. d. state. Thus, a Poisson effect was seen caused by spring-back. The measurements were slightly disturbed in this cycle by a climate chamber

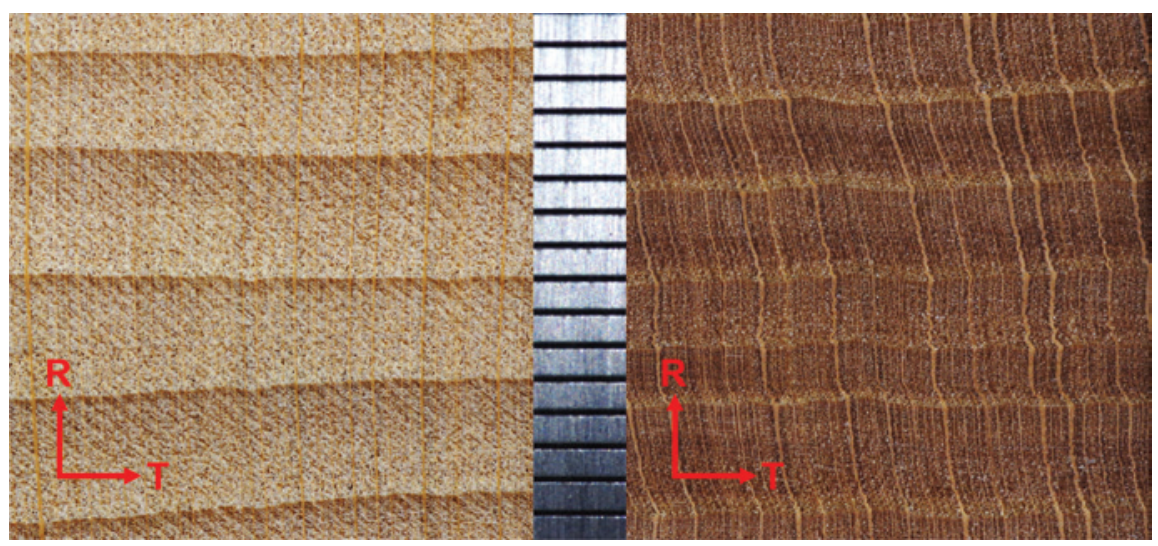

Figure 3: Photographs of beech samples before (left) and after densification (right) in the RT-plane cut with a circular saw blade from the middle region of the boards.

Distance of black lines on scale bar corresponds to $1 \mathrm{~mm}$. 
breakdown during the second swelling cycle, but most likely, the behavior of further cycles was not affected.

Figure 5 shows the mean density and mass of the samples in the course of the swelling-shrinkage cycles. A density decrement of the $\mathrm{dW}$ samples is visible but the absolute mass remains constant measured under identical conditions. Density seems to converge to $\approx 830 \mathrm{~kg} \mathrm{~m}^{-3}$, while the density of the reference samples is about $740 \mathrm{~kg} \mathrm{~m}^{-3}$ conditioned at $85 \% \mathrm{RH}$. Thus, the CR decreased from initially $43 \%$ to about $8 \%$ (back-calculation to $10 \%$ $\mathrm{MC})$. While the volume of $\mathrm{dW}$ samples increased, their capacity for water adsorption was not affected, because the mass changes were at a constant level. For both dW and $\mathrm{nW}$, the EMCs of $\approx 15 \%$ (at $85 \% \mathrm{RH}$ ) were calculated in each cycle. Repeated o.d. at $103^{\circ} \mathrm{C}$ for $48 \mathrm{~h}$ did not influence the capacity of moisture uptake.

Calculating the differential swelling and shrinkage coefficients for the different cycles (Figure 6) leads to further insights into the behavior of dW, as the strains are scaled over differences in MC; thus, the absolute water uptake mass is cancelled out. Here, the reference state for strain calculation in each cycle is the initial (dry) state of the cycle itself. For dW samples, the swelling and shrinkage coefficients are converging, i.e. the spring-back decreases. Surprisingly, both coefficients of dW samples in the R-direction converged to a value of 0.007 per $\%$, whereas this value was 0.003 per $\%$ in the T-direction.
The data of dW samples in the R-direction are remarkably higher than those of the $\mathrm{nW}$, whereas they are lower in the $\mathrm{T}$-direction. The $\mathrm{nW}$ references display a reversible swelling and shrinkage with differential coefficients of 0.002 per $\%$ in the R-direction and 0.004 per $\%$ in the T-direction, which correspond to the literature values of beech wood (Niemz et al. 2015).

The much higher swelling coefficients obtained after significant shape recovery within multiple cycles of moistening and drying indicate a weaker structural arrangement of the amorphous cell wall constituents. The same amount of water (same relative mass uptake) exerts an internal imbibition pressure, which is able to strain the partially recovered wood cell wall to a greater extent than for nW. In a phenomenological sense, swelling is stopped, when polymer network stresses are in equilibrium with the imbibition pressure of adsorbed water at a given MC (Kulasinski et al. 2015). The extent of internal damage to the cell wall (as observed in Bao et al. 2017) and its influence, however, needs further confirmation. Densification temperature, targeted CR and cooling rate significantly influence the resulting physical properties (Hill et al. 2012; Kutnar and Kamke 2012; Dubey et al. 2016).

The shape recovery, on the other hand, which could be observed as a separate process within the swelling of $\mathrm{dW}$, originates from preserved residual stresses of the densification procedure. The elastic energy responsible for

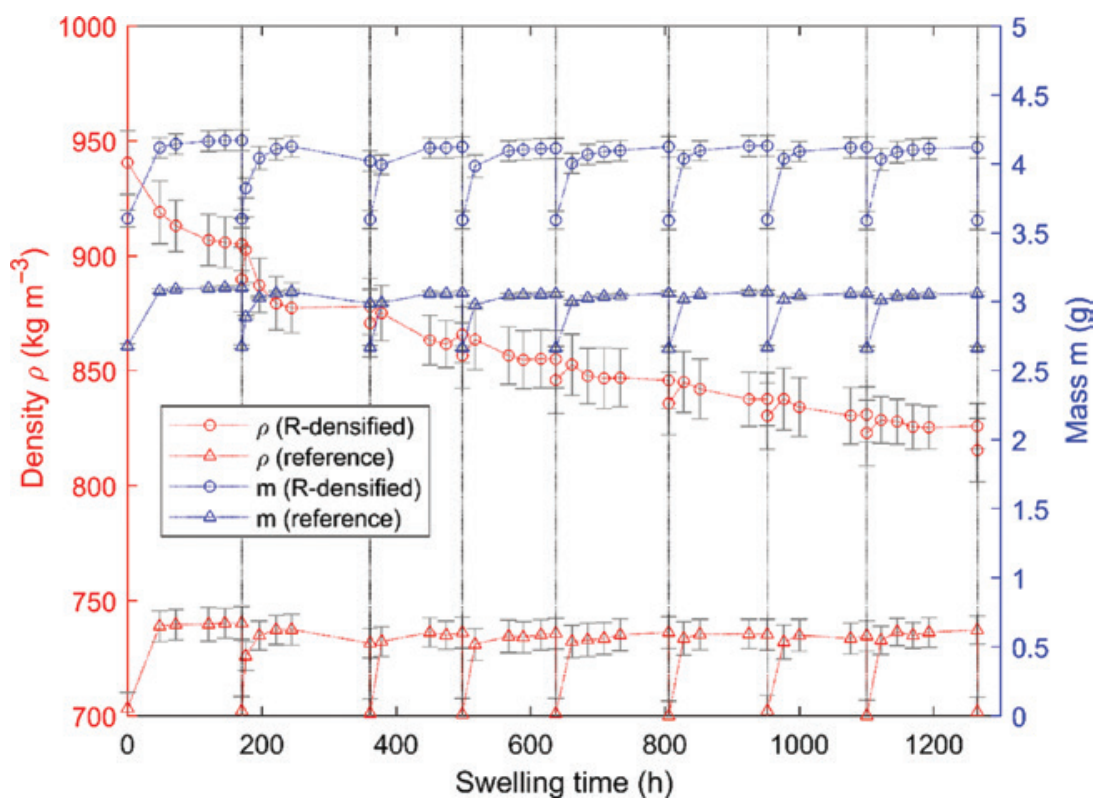

Figure 5: Recorded densities and samples weights over eight swelling and eight shrinkage cycles.

States before and after initial oven-drying are shown at $t=0$. Dotted lines represent linear interpolation between measured points. Vertical black dotted lines represent the end of swelling cycle, oven-drying (for $48 \mathrm{~h}$, not considered on the time axis) and the start of new swelling cycle. Markers represent mean values and gray error-bars represent positive and negative standard deviations. 


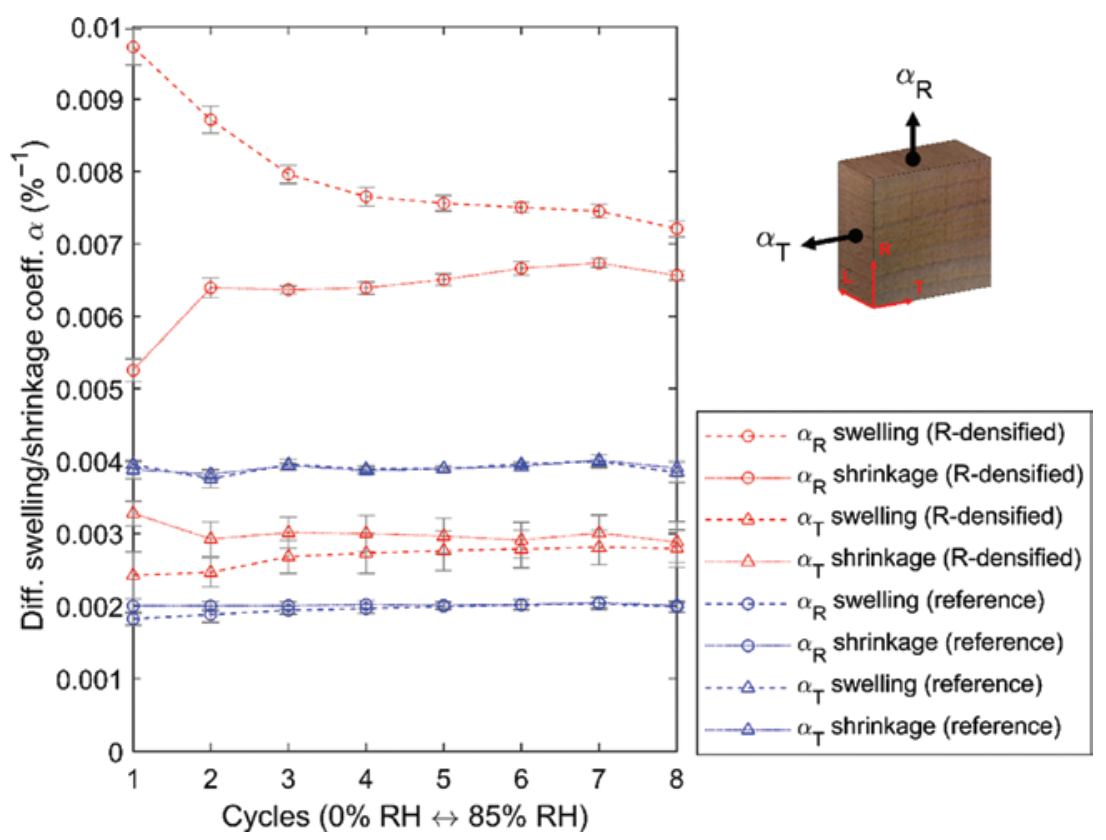

Figure 6: Calculated differential swelling and shrinkage coefficients over eight cycles for densified and native samples in the R-and T-directions.

Reference lengths for strains necessary for coefficient calculation at cycle $n$ are lengths from shrinkage of cycle $n-1$ for swelling coefficients, and lengths from swelling of cycle $\mathrm{n}$ for shrinkage coefficients. Lines represent linear interpolation between calculated points. Markers represent mean values and gray error-bars represent positive and negative standard deviations.

spring-back is stored mainly in the crystalline cellulose (Navi and Heger 2004). Over multiple swelling cycles, the additional internal stresses are eventually depleted by releasing strains. Each time the material swells, the sum of residual and applied imbibition forces is able to overcome the forces restraining the compressed shape, i.e. strains get released until an internal equilibrium is reached. In a next imbibition cycle, less residual stress will allow for less strain release. The strains are thus directly attributed to shape recovery, i.e. to unbuckling of the cell walls to some extent. This is in accordance with the observed asymptotic behavior of the shape recovery component converging to a limit value.

\section{Swelling pressure}

Measurement of biaxial swelling pressure (Figure 7) demonstrates that higher swelling pressures (in both $\mathrm{R}$ - and T-directions) are generated by the dW than the nW. Swelling pressure depends in a complex manner on swelling capacity, material stiffness and boundary conditions, which make an interpretation difficult. Likely, several results are due to the biaxial restraining, such

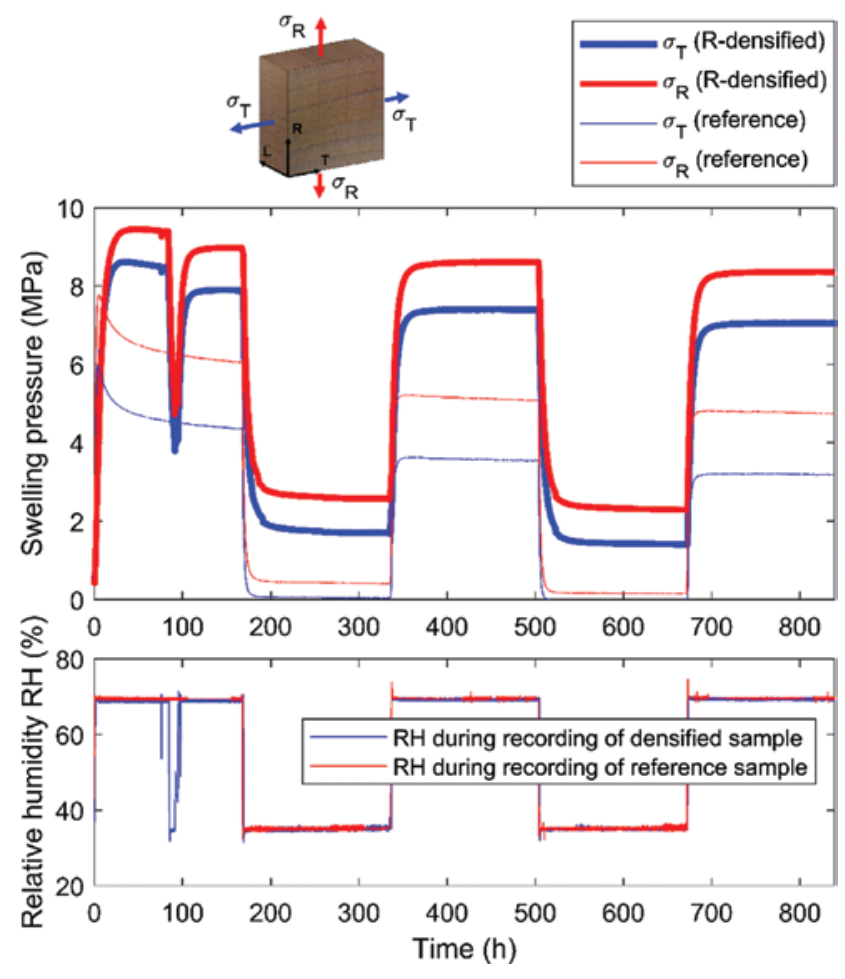

Figure 7: Biaxial restrained swelling pressures of native and densified wood in the R- and T-directions starting from the dry state at $\mathrm{t}=0$ over three moistening cycles along recorded $\mathrm{RH}$. 
as the shape recovery entailing the highest contribution to swelling pressure of $\mathrm{dW}$, and the higher value in the $\mathrm{T}$-direction compared to the $\mathrm{nW}$. The higher values of $\mathrm{dW}$ are in accordance with the literature data (Blomberg and Persson 2007). A maximal swelling pressure of $9.3 \mathrm{MPa}$ was reached in the R-direction for the R-densified samples. Considering the pronounced shape recovery, this value is slightly lower or equal to the compression strength of the sample under these conditions (in the biaxial stress state and changing $\mathrm{MC}$ ). For swelling-shrinkage cycles with varying $\mathrm{RH}$ between 70 and 35\% (Figure 6), corresponding to a realistic indoor climate variation within Central Europe, swelling pressures in both $\mathrm{R}$ - and T-directions of dW did not decrease in the same extent as in the case of nW. Considering an application as swelling dowels in timber joints, $\mathrm{dW}$ shows enhanced reliability compared to $\mathrm{nW}$, where the contact pressure in the dry state is eventually completely lost (Figure 6, after $500 \mathrm{~h}$ ) caused by complex coupled mechanisms such as visco-elasticity, mechano-sorption and plasticity.

\section{Swelling under load}

For an application as a swelling dowel in a timber joint, the conducted swelling pressure measurement represents the extreme case of very stiff connecting elements (e.g. wood on steel). In reality, the connecting elements that represent the bearing for the swelling of the dowel are made out of timber products with a limited transverse stiffness. The swelling behavior within an elastic embedding represents a more realistic investigation scenario. There, the swelling happens against an unknown restraining pressure. Figure 8 shows the obtained swelling strains over time under different applied loads for two subsequent different climates ( 65 and $85 \% \mathrm{RH}$ ). Based on an analogous rheological model of wood, the total strain can be interpreted as an additive effect of hygro-elastic, elastic, visco-elastic and mechano-sorptive strains, while the plasticity can be largely excluded under loads below a significant yield (Fortino et al. 2009; Hassani et al. 2015). As is visible, elastic strains, which instantly appear at $t=0$, are fully recovered after $336 \mathrm{~h}$ for both $\mathrm{nW}$ and $\mathrm{dW}$. In the case of dW, the elastic strain was higher than for $\mathrm{nW}$ for the same loads meaning that the transverse compression stiffness has been decreased as a result of densification. This observation is in accordance with the cell wall damage leading to higher hygroscopic swelling coefficients as observed earlier. The visco-elastic strains recovered at least partly within the 48-h interval after unloading.

In the graph of the nW (Figure 8a), it can be recognized that the visco-elastic strain dominated the swelling strain under a stress of up to $7.44 \mathrm{MPa}$ in swelling from 0 to $65 \%$ RH and up to $5.58 \mathrm{MPa}$ in swelling from 65 to $85 \%$ $\mathrm{RH}$ only. At these stresses, the limit of linearity in creep is
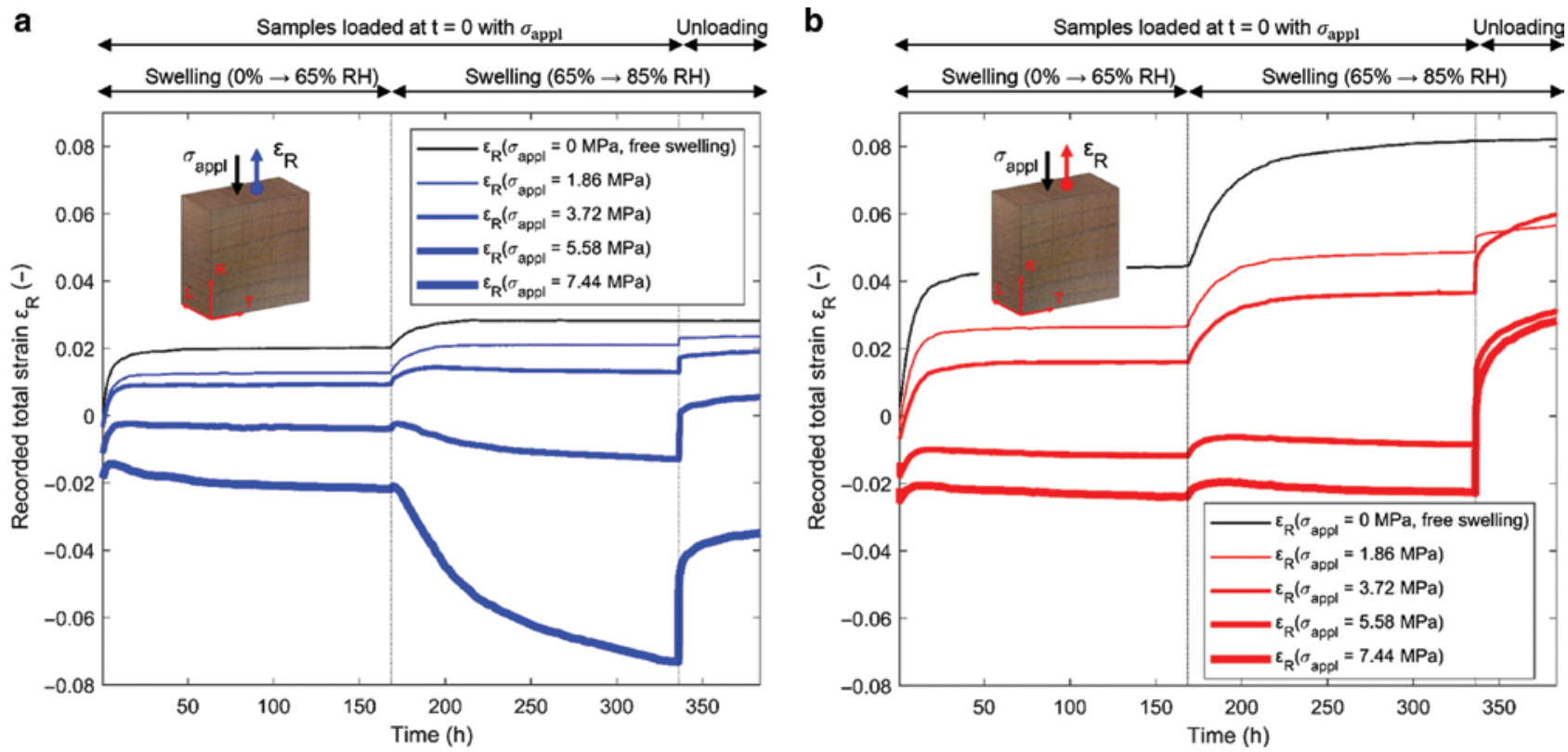

Figure 8: Combined swelling and creep strains measured under different uniaxial loadings over time (and eventual unloading) while reaching sorption equilibrium of samples in $65 \% \mathrm{RH}$ and $85 \%$ RH climates from an initially dry state.

(a) Native (reference) beech samples, and (b) R-densified beech samples. 
reached and a non-linear pattern is observed for the nWs at higher stresses. Such a limit of linearity is not visible for the dWs. Shape recovery due to water uptake is observed even under loading. Forty-eight hours after unloading (at $384 \mathrm{~h}$ ), all densified samples exhibited positive strains, although no systematic patterns are visible among the samples. Accordingly, the long-term swelling pressure of $\mathrm{nW}$ will be limited to a threshold value of the non-linear creep. This can also be recognized in Figure 7, where the initially high swelling pressures of 6 and $8 \mathrm{MPa}$ in the Tand R-directions, respectively, decreased quickly due to pronounced and fast relaxation. This problem, however, did not affect dW. Superior properties of dW in terms of higher and reliable swelling pressures, especially under variable climatic conditions, could be demonstrated.

\section{Double shear lap joint tests with cylindrical dovetailed dowels}

Force-displacement curves of the tested jointsarepresented in Figure 9. For the joints with densified dowels, a mean joint stiffness of $\bar{x}_{K_{s}}=4.58 \mathrm{kN} \mathrm{mm}^{-1}$ with $s_{K_{s}}=0.31 \mathrm{kN} \mathrm{mm}^{-1}$ is obtained. For the joints with $\mathrm{nW}$ dowels, slightly lower values of $\bar{x}_{K_{s}}=4.21 \mathrm{kN} \mathrm{mm}^{-1}$ with $s_{K_{\mathrm{s}}}=0.52 \mathrm{kN} \mathrm{mm}^{-1}$ are seen. This difference, though not statistically significant, is attributed to the higher swelling pressures of the densified dowels. Both stiffness and ultimate load were affected by densified dowels. All joints failed beyond the bearing

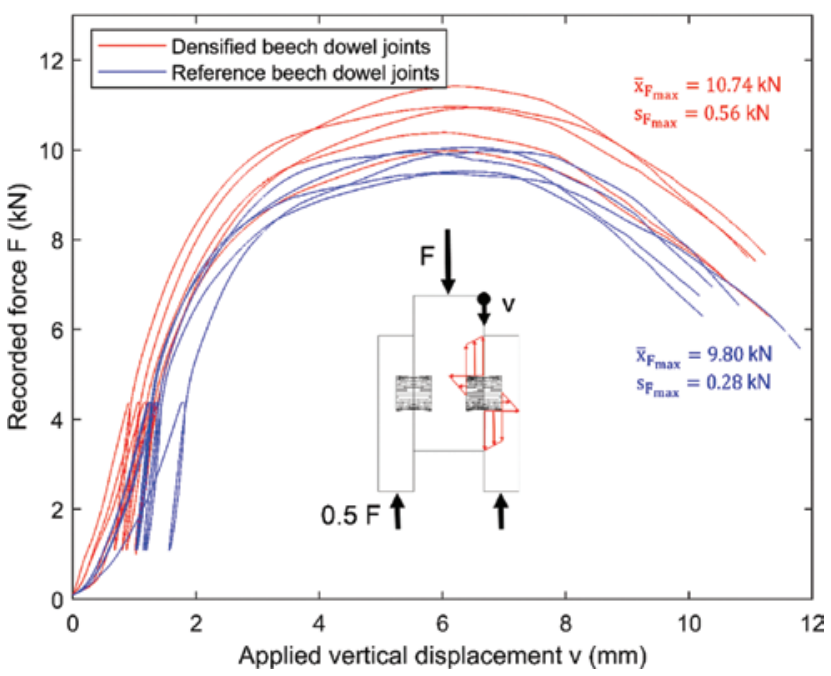

Figure 9: Force-displacement curves for double shear lap. Samples loaded until $40 \%$ of presumed maximal force $F_{\text {max,est }}$, then load removed until $10 \%$ of $F_{\text {max,est }}$, then loaded until failure (following standard EN 26 891:1991). An initial load of $0.1 \mathrm{kN}$ was applied before start of measurement. capacity of spruce boards because of internal dowel rotation in the load direction. This is not an optimal failure mode of such a joint, because in structural timber engineering the connectors should preferably fail and not the connecting elements. However, the geometrical and physical constraints for manufacturing suitable swelling dovetail dowels did not allow for another possible joint design. Constraints such as initial insertion of the dowel, degree of freedom for initial rotation of the dowel, while preventing out-of-plane movement until friction locking, and reliable contact pressures need to be considered. Thus, it is recommended for structures using such a joint geometry to be designed based on the bearing capacity of the spruce boards at the joint.

Advantages of the presented joints are as follows: (i) an easy joint assembly that can be automated by computer-controlled systems, (ii) an initial degree of freedom of rotation for achieving final assembly after joining the wood parts and for correcting assembly tolerances (e.g. for wooden truss structures), (iii) a long-term rigidity by achieving form-and-friction locking due to high and reliable swelling pressures, (iv) a generic higher ductility at failure load compared to native hardwood dowels, given a dowel failure (Jung et al. 2008) and (v) use of the highly abundant beech wood. Disadvantages can be seen in the more complex production process including a densification step and a CNC milling step, and in the fact that the beech dowels do not permit applications under outdoor conditions because of the low durability. So far, the dimensioning of any such dowel connections can only be done under consideration of minimum swelling as a sum of the hygro-elastic swelling and the shape recovery. Precise predicting dowel deformation is not yet possible, as the material behavior of $\mathrm{dW}$ is by far too complex and scarcely known. An in-depth characterization and the development of a comprehensive non-linear model for predicting swelling would be required. Despite such restrictions, the data provided in this study can be useful for simple design as was demonstrated by the application examples with double-dovetail swelling dowel.

\section{Conclusions}

The exposure of dW to alternating dry and humid conditions provided new insights. The shape recovery and the hygroscopic swelling could be separately assessed. The differential swelling coefficient in the densification direction, which is independent of shape recovery, was found to be around 3.5 times higher for beech dW than for beech $\mathrm{nW}$ in the same direction after spring-back had ceased 
for $0-85 \%$ RH cycles. Beech dW showed higher and more persistent swelling pressures than beech $\mathrm{nW}$. Whereas $\mathrm{nW}$ showed non-linear creep for swelling under mechanical load, dW was able to swell under load. Based on these observations, R-densified beech shows superior properties for use as a swelling dowel compared to $\mathrm{nW}$, even though there are densification damages in the cell wall structure. In a design study for robotic fabrication, a reliable form-and-friction locking was achieved after simple assembly and initial rotational degree of freedom.

Acknowledgments: We sincerely thank W. Sonderegger for providing the densification protocol, and M. Chanana, E.V. Bachtiar and F.K. Wittel for helpful discussions.

Author contributions: All the authors have accepted responsibility for the entire content of this submitted manuscript and approved submission.

Research funding: None declared.

Employment or leadership: None declared.

Honorarium: None declared.

\section{References}

Adriaenssens, S., Gramazio, F., Kohler, M., Menges, A., Pauly, M. Advances in Architectural Geometry 2016. vdf Hochschulverlag an der ETH Zürich, Zürich, 2016.

Anshari, B., Guan, Z.W., Kitamori, A., Jung, K., Hassel, I., Komatsu, K. (2011) Mechanical and moisture-dependent swelling properties of compressed Japanese cedar. Constr. Build. Mater. 25:1718-1725.

Bachtiar, E.V. Material Characterization of Wood, Adhesive and Coating of Cultural Heritage Under Various Climatic Conditions. Dissertation, ETH Zurich, Zürich, Switzerland, 2017.

Bao, M., Huang, X., Jiang, M., Yu, W., Yu, Y. (2017) Effect of thermohydro-mechanical densification on microstructure and properties of poplar wood (Populus tomentosa). J. Wood Sci. 63:591-605.

Blomberg, J. Mechanical and Physical Properties of Semi-isostatically Densified Wood. Dissertation, Luleå University of Technology LTU, Luleå, Sweden, 2006.

Blomberg, J., Persson, B. (2007) Swelling pressure of semi-isostatically densified wood under different mechanical restraints. Wood Sci. Technol. 41:401-415.

Blomberg, J., Persson, B., Bexell, U. (2006) Effects of semi-isostatic densification on anatomy and cellshape recovery on soaking. Holzforschung 60:322-331.

Buchelt, B., Dietrich, T., Wagenfuehr, A. (2014) Testing of set recovery of unmodified and furfurylated densified wood by means of water storage and alternating climate tests. Holzforschung 68:23-28.

Dubey, M.K., Pang, S., Chauhan, S., Walker, J. (2016) Dimensional stability, fungal resistance and mechanical properties of radiata pine after combined thermo-mechanical compression and oil heat-treatment. Holzforschung 70:793-800.
Fortino, S., Mirianon, F., Toratti, T. (2009) A 3D moisture-stress FEM analysis for time dependent problems in timber structures. Mech. Time-Depend. Mater. 13:333-356.

Gramazio, F., Kohler, M. The Robotic Touch: How Robots Change Architecture : Gramazio \& Kohler Research ETH Zurich 2005-2013. Park Books, Zürich, 2014.

Guan, Z., Komatsu, K., Jung, K., Kitamori, A. (2010) Structural characteristics of beam-column connections using compressed wood dowels and plates. In: WCTE 2010 - World Conference on Timber Engineering, Trentino, Italy.

Hassani, M.M., Wittel, F.K., Hering, S., Herrmann, H.J. (2015) Rheological model for wood. Comput. Methods Appl. Mech. Eng. 283:1032-1060.

Heger, F., Groux, M., Girardet, F., Welzbacher, C., Rapp, A.O., Navi, P. (2004) Mechanical and Durability Performance of THM-Densified Wood. Final Workshop COST Action E22 'Environmental Optimisation of Wood Protection', 22nd-23rd March 2004, Lisboa, Portugal.

Hering, S. Charakterisierung und Modellierung der Materialeigenschaften von Rotbuchenholz zur Simulation von Holzverklebungen. Dissertation, ETH Zurich, 2011.

Hill, C.A.S., Ramsay, J., Keating, B., Laine, K., Rautkari, L., Hughes, M., Constant, B. (2012) The water vapour sorption properties of thermally modified and densified wood. J. Mater. Sci. 47:3191-3197.

Holzer, S., Loferski, J., Dillard, D. (1989) A review of creep in wood - concepts relevant to develop long-term behavior predictions for wood structures. Wood Fiber Sci. 21:376-392.

Ispas, M. (2013) Experimental investigations on swelling pressure of natural and heat-treated ash wood. Bull. Transilv. Univ. Brasov Ser. II - For. Wood Ind. Agric. Food Eng. 6:55-62.

Jung, K., Kitamori, A., Komatsu, K. (2008) Evaluation on structural performance of compressed wood as shear dowel. Holzforschung 62:461-467.

Kulasinski, K., Guyer, R., Derome, D., Carmeliet, J. (2015) Water adsorption in wood microfibril-hemicellulose system: role of the crystalline-amorphous interface. Biomacromolecules 16:2972-2978.

Kutnar, A., Kamke, F.A. (2012) Compression of wood under saturated steam, superheated steam, and transient conditions at 150 degrees C, 160 degrees C, and 170 degrees C. Wood Sci. Technol. 46:73-88.

Kutnar, A., Kamke, F.A., Sernek, M. (2008) The mechanical properties of densified VTC wood relevant for structural composites. Holz Roh-Werkst. 66:439-446.

Kutnar, A., Kamke, F.A., Sernek, M. (2009) Density profile and morphology of viscoelastic thermal compressed wood. Wood Sci. Technol. 43:57-68.

Laine, K. Improving the Properties of Wood by Surface Densification. Dissertation, Aalto University, Helsinki, Finland, 2014.

Laine, K., Belt, T., Rautkari, L., Ramsay, J., Hill, C.A.S., Hughes, M. (2013) Measuring the thickness swelling and set-recovery of densified and thermally modified Scots pine solid wood. J. Mater. Sci. 48:8530-8538.

Menges, A., Sheil, B., Glynn, R., Skavara, M.; Universität Stuttgart, Institute for Computational Design and Construction. Fabricate: Rethinking Design and Construction. Cambridge, Riverside Architectural Press, ON, 2017a.

Menges, A., Schwinn, T., Krieg, O.D. Advancing Wood Architecture: A Computational Approach. Routledge, London, 2017b. 
Morsing, N., Hoffmeyer, P. Densification of Wood: The Influence of Hygrothermal Treatment on Compression of Beech Perpendicular to Grain. Dissertation, Technical University of Denmark DTU, Kongens Lyngby, Denmark, 1998.

Navi, P., Girardet, F. (2000) Effects of thermo-hydro-mechanical treatment on the structure and properties of wood. Holzforschung 54:287-293.

Navi, P., Heger, F. (2004) Combined densification and thermo-hydromechanical processing of wood. MRS Bull. 29.

Navi, P., Heger, F. Comportement thermo-hydromécanique du bois. Presses polytechniques et universitaires romandes, Lausanne, Switzerland, 2005.

Niemz, P., Ozyhar, T., Hering, S., Sonderegger, W. (2015) Zur Orthotropie der physikalisch-mechanischen Eigenschaften von Rotbuchenholz. Bautechnik 92:3-8.

Ożyhar, T. Moisture and Time-dependent Orthotropic Mechanical Characterization of Beech Wood. Dissertation, ETH Zurich, Zürich, Switzerland, 2013.
Palma, P., Kobel, P., Minor, A., Frangi, A. (2016) Dowelled timber connections with internal members of densified veneer wood and fibre-reinforced polymer dowels. In: WCTE 2016 - World Conference on Timber Engineering, Vienna, Austria.

Sandberg, L.B., Bulleit, W.M., Reid, E.H. (2000) Strength and stiffness of oak pegs in traditional timber-frame joints. J. Struct. Eng.-ASCE 126:717-723.

Sandberg, D., Haller, P., Navi, P. (2013) Thermo-hydro and thermohydro-mechanical wood processing: an opportunity for future environmentally friendly wood products. Wood Mater. Sci. Eng. 8:64-88.

Skyba, O. Durability and Physical Properties of Thermo-hygromechanically (THM)-densified Wood. Dissertation, ETH Zurich, Zürich, Switzerland, 2008.

Ugolev, B.N. (2014) Wood as a natural smart material. Wood Sci. Technol. 48:553-568.

Wolcott, M.P., Shutler, E.L. (2003) Temperature and moisture influence on compression-recovery behavior of wood. Wood Fiber Sci. 35:540-551. 